\title{
Analysis of Influencing Factors and Development Path of Cross-Border E-Commerce of Agricultural Products under The Background of Agricultural Supply-Side Structural Reform
}

\author{
Liying Zhao ${ }^{1}$, Qing $\mathbf{L i}^{2}$ \\ ${ }^{1}$ Institute of Management, Dalian Polytechnic University, No. 1st Qinggongyuan, Ganjingzi,, \\ Dalian, China \\ ${ }^{2}$ Institude of Management, Dalian Polytechnic University, No. 1st Qinggongyuan, Ganjingzi,, \\ Dalian, China \\ Qing625@163.com
}

Keywords: Cross-border e-commerce of agricultural products, Agricultural supply-side reform, Structural mode of ISM explanation

Abstract: In recent years, China is under the background of agricultural supply-side reform, and it is urgent to realize the goal of agricultural development of "de-stocking, cost reduction and Add short board". The rapid development of cross-border e-commerce in agricultural products has become an important means to improve the agricultural economy. This paper lists 12 specific indicators from the service, policy, quality and infrastructure of cross-border e-commerce of agricultural products. The factors influencing the development of cross-border e-commerce of agricultural products were analyzed by the ISM model. Based on the perspective of agricultural supply-side reform policy, the paper proposes the development path of cross-border e-commerce of agricultural products.

\section{Introduction}

In recent years, Chinese e-commerce environment has been developing rapidly. Both the number of netizens and the number of listed e-commerce enterprises are on the rise. In the environment of economic globalization, the scope of e-commerce transactions is not only limited to domestic scope. According to the 2017 Chinese e-commerce market data monitoring report provided by the ecommerce center, China's export cross-border e-commerce transactions reached 6.3 trillion Yuan in 2017, 14.5\% more comparing the same period. The rapid development of Chinese cross-border ecommerce has led to the positive growth of the export of agricultural products, and has become a new way for farmers to create wealth and increase their income.

In recent years, domestic scholars have gradually focused on the study of cross-border ecommerce of agricultural products. From the perspective of full sample and sample, Zhaoyang Lu analyzed the influencing factors of cross-border e-commerce of agricultural products by using questionnaire as data support (Zhaoyang Lu, 2018). Xueqiang Luo and Lizhen Huang studied the development strategy of cross-border e-commerce of agricultural products with Chinese 
characteristics from the perspective of macro policies and micro environment (Xueqiang Luo, 2017). Wei Liu pointed out the problems existing in the development of cross-border e-commerce of agricultural products in China. Based on the smile theory, he constructed the development path of cross-border e-commerce of agricultural products (Wei Liu, 2017). However, there are few literatures studying the influencing factors of cross-border e-commerce of agricultural products. To accelerate the development of cross-border e-commerce of agricultural products, it is necessary to analyze its influencing factors. Moreover, no scholar has published a study on the development of cross-border e-commerce of agricultural products from the perspective of agricultural supply-side reform.

At present, Chinese agricultural trade is affected by its price and cost. Compared with the prices of international agricultural products, the prices of most agricultural products are too high, which leads to the imbalance and insufficient supply of agricultural products for cross-border e-commerce in China. Cross-border e-commerce of agricultural products is an innovative way combining modern network technology with agricultural production. In the context of economic globalization, it promotes the rapid realization of information flow, logistics and capital flow. Under the background of agricultural supply-side reform, China urgently realizes the goal of "destocking, reducing cost and reinforcing shortage" in agricultural development. Under the background of supply-side reform, it is of great significance to study how to develop cross-border e-commerce of agricultural products for realizing agricultural supply-side reform and promoting the development of China's agricultural economy.

\section{Analysis of factors influencing cross-border e-commerce of agricultural products based on ISM model}

Interpretive Structural Modeling is a method of analyzing complex socioeconomic systems was created in 1973 by American professor J. Walter. The basic principle to explain the structure model is: use directed connection graph to describe the correlation among the subsystem elements to be analyzed. In this way, the model of element aggregation with hierarchy and logic is expressed. (Guogang Li, 2013).

The analysis steps are:

Firstly, select the systematic elements of the research subject;

Secondly, through the study, the relationship among the elements is determined, and the adjacency matrix and reachable matrix are established.

Finally, decompose the resolvable matrix and establish the structure model.

The following, the influencing factors of cross-border e-commerce of agricultural products are analyzed according to the method of explaining the structural model. (Xianbing Ping, 2014).

\subsection{Factor Selection}

By summarizing relevant research literature on cross-border e-commerce development of agricultural products. Adopting Delphi method, the key influencing factors of cross-border ecommerce development of agricultural products are listed from several aspects, such as service, policy, quality and infrastructure. Specific indicators are shown in table 1.

\subsection{Set up The Adjacency Matrix A}

According to the factors influencing cross-border e-commerce of agricultural products which listed in table 1.The following adjacency matrix A model can be established. It is mainly used to show the direct connection between the elements of the system. When $\mathrm{Si}=1$, it indicates that $\mathrm{Si}$ has 
direct influence on $\mathrm{Sj}$; When $\mathrm{Si}=0$, it indicates that $\mathrm{Si}$ has no direct influence on $\mathrm{Sj}$.

Table 1 Factors influencing the development of cross-border e-commerce of agricultural products.

\begin{tabular}{|c|c|c|c|}
\hline symbol & influence factor & symbol & influence factor \\
\hline S1 & The enterprise scale & S7 & Credit system construction \\
\hline S2 & Consumer satisfaction & S8 & Distribution efficiency \\
\hline S3 & The logistics cost & S9 & Infrastructure construction \\
\hline S4 & Customs clearance efficiency & S10 & $\begin{array}{c}\text { System of policies and } \\
\text { regulations }\end{array}$ \\
\hline S5 & $\begin{array}{c}\text { Agricultural products cross-border e- } \\
\text { commerce talent cultivation }\end{array}$ & S11 & $\begin{array}{c}\text { Cross-border e-commerce } \\
\text { market demand for agricultural } \\
\text { products }\end{array}$ \\
\hline S6 & $\begin{array}{c}\text { Cross-border e-commerce logistics } \\
\text { technology }\end{array}$ & S12 & agricultural product quality \\
\hline
\end{tabular}

Adjacency matrix $A=\left[\begin{array}{cccccccccccc}0 & 1 & 1 & 0 & 1 & 1 & 1 & 0 & 1 & 0 & 0 & 0 \\ 0 & 0 & 0 & 0 & 1 & 1 & 0 & 0 & 0 & 0 & 1 & 0 \\ 0 & 0 & 0 & 0 & 0 & 0 & 1 & 0 & 1 & 0 & 0 & 0 \\ 0 & 1 & 0 & 0 & 1 & 1 & 0 & 0 & 0 & 0 & 1 & 0 \\ 0 & 0 & 0 & 0 & 0 & 1 & 0 & 0 & 0 & 0 & 0 & 0 \\ 0 & 0 & 0 & 0 & 0 & 0 & 0 & 0 & 0 & 0 & 0 & 0 \\ 0 & 1 & 0 & 1 & 1 & 1 & 0 & 0 & 0 & 0 & 1 & 0 \\ 0 & 1 & 0 & 0 & 1 & 1 & 0 & 0 & 0 & 0 & 1 & 1 \\ 0 & 1 & 0 & 1 & 1 & 1 & 0 & 1 & 0 & 0 & 1 & 0 \\ 1 & 0 & 0 & 1 & 1 & 0 & 1 & 0 & 1 & 0 & 1 & 0 \\ 0 & 1 & 0 & 0 & 1 & 1 & 0 & 0 & 0 & 0 & 0 & 0 \\ 0 & 1 & 0 & 0 & 0 & 0 & 0 & 0 & 0 & 0 & 1 & 0\end{array}\right]$

\subsection{Set up the Reachable Matrix M}

Adding the adjacency matrix A to the identity matrix I, according to the Boolean algebra operation rule , the matrix perform self-multiplication, until all the products are equal after a certain exponentiation, the product of which is equal is the reachable matrix $\mathrm{M}$.

The following results were obtained by MATLAB software calculation:

Reachable matrix $M=\left[\begin{array}{llllllllllll}1 & 1 & 1 & 0 & 1 & 1 & 0 & 1 & 1 & 0 & 1 & 1 \\ 0 & 1 & 0 & 0 & 1 & 1 & 0 & 0 & 0 & 0 & 0 & 0 \\ 0 & 1 & 1 & 1 & 1 & 1 & 1 & 1 & 1 & 0 & 1 & 1 \\ 1 & 0 & 0 & 1 & 1 & 1 & 1 & 1 & 1 & 0 & 1 & 1 \\ 0 & 0 & 0 & 0 & 1 & 1 & 0 & 0 & 0 & 0 & 0 & 0 \\ 0 & 0 & 0 & 0 & 0 & 1 & 0 & 0 & 0 & 0 & 0 & 0 \\ 1 & 1 & 0 & 1 & 1 & 1 & 1 & 1 & 1 & 0 & 0 & 0 \\ 0 & 1 & 0 & 1 & 1 & 1 & 0 & 1 & 0 & 0 & 0 & 0 \\ 0 & 1 & 1 & 1 & 1 & 1 & 1 & 0 & 1 & 0 & 1 & 1 \\ 1 & 1 & 1 & 1 & 1 & 1 & 1 & 1 & 1 & 1 & 0 & 0 \\ 0 & 0 & 0 & 0 & 1 & 1 & 0 & 0 & 0 & 0 & 1 & 0 \\ 0 & 1 & 0 & 0 & 1 & 1 & 0 & 0 & 0 & 0 & 1 & 1\end{array}\right]$




\subsection{Decompose THE Reachable Matrix}

Reachable set $\mathrm{R}(\mathrm{Si})$ : the set of elements in the row corresponding to the element $\mathrm{Si}$ in the reachable matrix, including the column corresponding to the matrix element 1 .

Leading set Q (Si): the set of elements in the column corresponding to the element $\mathrm{Si}$ in the reachable matrix, including the column corresponding to the matrix element 1.

Intersection $\mathrm{A}=\mathrm{R}(\mathrm{Si}) \mathrm{Q}(\mathrm{Si})$

In order to decompose the reachable matrix, we first list the reachable set and the first set and their intersection on the table, as shown in table 2.

Table 2 Reachable matrix, Leading set and Intersection.

\begin{tabular}{|c|c|c|c|}
\hline $\mathrm{i}$ & $\mathrm{R}(\mathrm{Si})$ & $\mathrm{Q}(\mathrm{Si})$ & $\mathrm{R}(\mathrm{Si}) \cap \mathrm{Q}(\mathrm{Si})$ \\
\hline 1 & 123568911 & 1471012 & 1 \\
\hline 2 & 256 & 1237891012 & 2 \\
\hline 3 & 234567891112 & 13910 & 39 \\
\hline 4 & 14567891112 & 3478910 & 14789 \\
\hline 5 & 56 & 12345789101112 & 5 \\
\hline 6 & 6 & 123456789101112 & 1479 \\
\hline 7 & 12456789 & 347910 & 148 \\
\hline 8 & 24568 & 1347810 & 3479 \\
\hline 9 & 23456791112 & 1347910 & 10 \\
\hline 10 & 1245678910 & 10 & 11 \\
\hline 11 & 5611 & 1391112 & 12 \\
\hline 12 & 2561112 & 134912 & \\
\hline
\end{tabular}

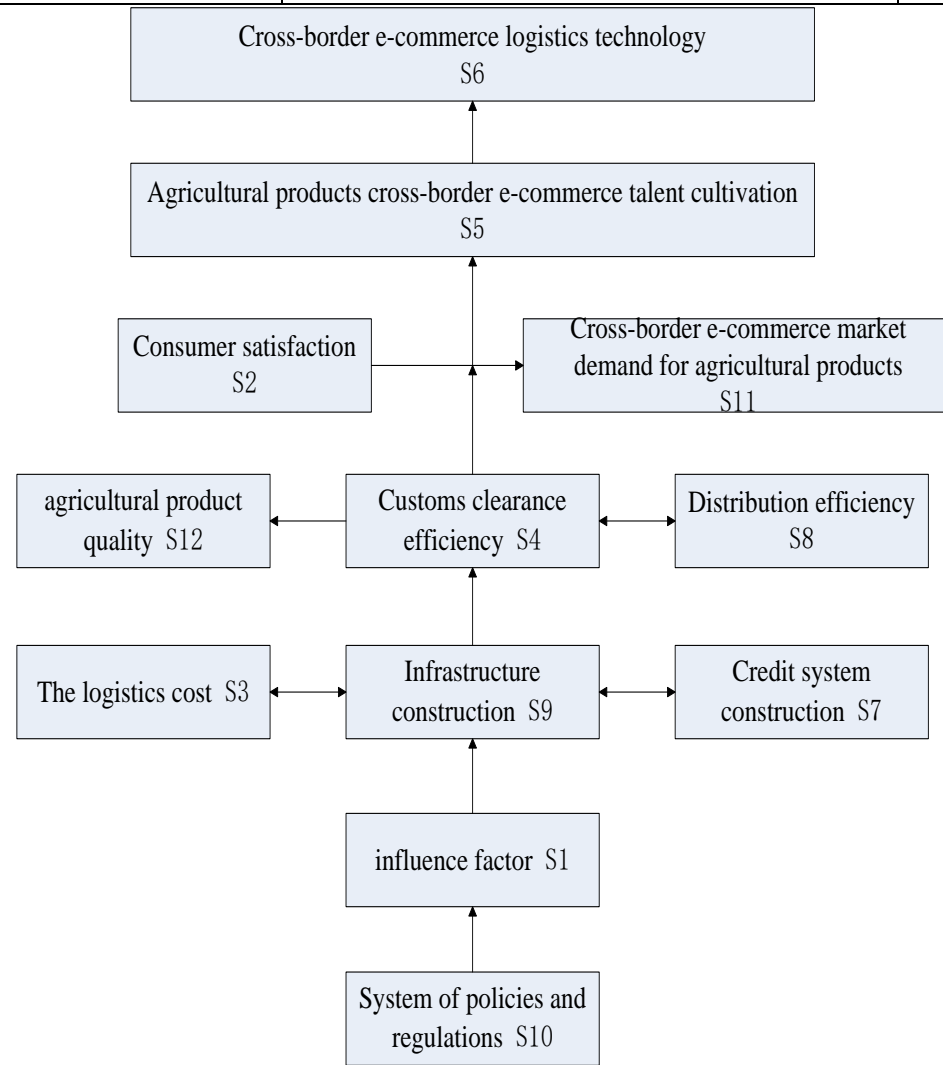

Figure 1 ISM model of factors influencing cross-border e-commerce development of agricultural products. 


\subsection{Hierarchical Decomposition}

The method of level decomposition is to extract the level according to the $\mathrm{R}(\mathrm{Si})=\mathrm{R}(\mathrm{Si})$ condition.

As $\mathrm{Si}=6$ meets the conditions, so S6 is the first indicator to be extracted, this means that S6 is the top level of the system. Then, all the elements related to 6 in table 1 were extracted. According to this principle, the classification layer by layer. The extraction process was omitted in this paper due to the long space. S10 is the last indicator to be extracted. The lowest end of the model is S10, Namely S10 is the root cause of system factors.

According to the extraction results, the interpretation structure model is drawn (as shown in figure 1).

3. The development path of cross-border e-commerce of agricultural products under the reform of agricultural supply-side structure

Based on the above model, it can be seen that the System of policies and regulations, credit system construction, infrastructure improvement, agricultural product quality and Agricultural products cross-border e-commerce talent cultivation have a great impact on the development of cross-border e-commerce of agricultural products. Based on the analysis of influencing factors, this paper proposes the development direction of cross-border e-commerce of agricultural products from the perspective of supply-side reform of agriculture.

\subsection{Macroeconomic Policy and Environmental Regulation}

The development of cross-border e-commerce of agricultural products is inseparable from the macro-control of national policies.

1) Strengthen the policy support for cross-border e-commerce agricultural products. According to the report provided by the e-commerce research center, the cross-border e-commerce sellers of agricultural products are mainly in the relatively developed pilot areas in Guangdong, Zhejiang, Jiangsu, Shanghai and Shenzhen. However, few enterprises in other regions achieve cross-border trade of agricultural products, which is not conducive to the long-term and healthy development of cross-border e-commerce of agricultural products in China.

The state should expand the scope of policies, reduce the tax from cross-border e-commerce enterprises of agricultural products, expand the scale of e-commerce enterprises by reducing taxes, streamlining the tax refund process and relaxing lending policies, as such it is can achieve the balanced development of cross-border e-commerce enterprises in various regions of China. We will open up the market of agricultural products with Chinese characteristics, so that the featured agricultural products in different regions of China will be more circulated to foreign consumers.

2) The procedures of import and export clearance of agricultural products are tedious and complicated. Because there are many steps in clearance process, so it can increase the time that product carries, store. On the basis of affecting the quality of agricultural products, logistics cost is also increased, which is not conducive to the development of the industry. It will hinder the realization of the goal of reducing cost in the supply-side reform of agriculture in China.

Therefore, the state should adopt relevant policies to simplify the process of customs clearance. The customs commodity inspection system realizes joint information sharing, and the declaration of agricultural products shall not be repeatedly declared. We will increase the number of people involved in handling cross-border agricultural products clearance and improve the efficiency of the clearance of agricultural products. For the cargos inspected by the customs, the cost of inspection should be rationalized to reduce the cost of suppliers. 


\subsection{Establish a Sound Credit System}

On the one hand, the e-commerce market relies on the Internet environment, and the network information is virtual and open. There is no lack of online fraud and consumer personal information leakage among cross-border agricultural products e-commerce, which leads to consumers' deep distrust of cross-border e-commerce platforms. On the other hand, enterprises related to crossborder e-commerce of agricultural products have difficulty in financing and the imbalance of financial supply is insufficient, which leads to the slow development of cross-border e-commerce enterprises of agricultural products.

These phenomena greatly hinder the development of cross-border e-commerce of agricultural products. To fundamentally solve this kind of phenomenon, we need to establish a perfect credit system. (Yu Ding, 2016).

1) At present, cross-border e-commerce of agricultural products in China is mainly based on export. To expand market share, first of all, it is necessary to ensure that domestic suppliers provide genuine agricultural products, avoid releasing false information and create distrust among consumers. To register cross-border e-commerce entities, the registration on the e-commerce platform shall provide customers' personal identity information, enterprise related tax certificate, production qualification certificate, agricultural product inspection and quarantine certificate, certificate of origin and other relevant documents. The credit rating of each subject is evaluated through the interworking of network technology and credit information system. If a supplier is found to have substandard product, the e-commerce platform will immediately take off the products and publish notice. If the case is serious, the e-commerce platform can cooperate with the judicial department to deal with it.

2) Cross-border e-commerce enterprises should strengthen the confidentiality management of information. In the Internet environment, the problem of consumer information leakage often occurs.

E-commerce enterprises should strengthen information technology and protect the internal data of enterprises. Besides, the company should establish a confidentiality system. Employees who have access to sensitive information of customers should sign a confidentiality agreement to avoid the disclosure of information of buyers and sellers. Reduce the risk of information leakage of suppliers and consumers, establish trust mechanisms, and improve user satisfaction.

3) Agricultural financial institutions should exercise financial supervision over agricultural production enterprises. At present, the supply of agricultural finance is unbalanced. Financial institutions involved can force agricultural production enterprises to establish a good credit environment through the supervision of enterprise tax and finance, which has a great promoting effect on solving the financing problems of agricultural production enterprises.

\subsection{Perfecting the Construction of Infrastructure}

In the cross-border trade of agricultural products, there are often serious losses of agricultural products due to the imperfect infrastructure. To some extent, this phenomenon increases the cost of trade and reduces customer satisfaction, which is not conducive to the development of cross-border e-commerce of agricultural products. Infrastructure construction is an important shortcoming in the development of cross-border e-commerce of agricultural products. Infrastructure improvement is the guarantee of effective operation.

1) Agricultural products are characterized by strong seasonality and high rate of rot and damage. Complete logistics facilities are needed in cross-border transportation to guarantee the quality of agricultural products and avoid unnecessary product losses. Among the numerous agricultural products, fresh agricultural products have high requirements for cold chain logistics technology.

The transportation of fresh agricultural products must be based on mature cold chain fresh- 
keeping technology to ensure the quality of agricultural products and reduce resource consumption and waste in distribution. Therefore, China is in urgent need of the introduction of agricultural cold chain equipment and related technologies.

2) Providing comprehensive and mature logistics services are a necessary condition for the development of cross-border e-commerce. The construction of infrastructure is not limited to one mode. It is necessary to strengthen the infrastructure construction of various transportation modes such as land transport, sea transport and air transport.

3) In cross-border agricultural trade, foreign consumers are very concerned about the delivery time of products, so infrastructure construction should also shorten the delivery time of agricultural products as much as possible. This can not only guarantee the quality of agricultural products, but also enable customers to have better consumption experience and improve the market demand of cross-border e-commerce of agricultural products. Therefore, in the future development of crossborder e-commerce of agricultural products, it is suggested to establish overseas warehouses in countries with high demand. In addition, mature cold chain fresh-keeping technology should be used in the warehouse, and the type and quantity of agricultural products in the warehouse should be reasonably planned. The construction of overseas warehouses can effectively shorten the delivery time and reduce the transportation cost. And because of the short transport time, the quality of agricultural products can be guaranteed.

\subsection{Establish the Quality Standard System of Agricultural Products}

The quality of agricultural products is one of the important factors that restrain the development of cross-border e-commerce of agricultural products. To carry out agricultural supply-side reform, we should adhere to the quality of agricultural products. At present, cross-border e-commerce of agricultural products in China is mainly based on export. From the perspective of supply side, China does not have a strict standard for the quality of exported agricultural products. This leads to uneven quality of agricultural exports. Therefore, it is of vital importance to expand market demand, vigorously develop cross-border e-commerce of agricultural products, and carry out effective inspection, detection and monitoring of the quality of agricultural products. (Yongchao Yang., 2017).

1) According to the international standards for Inspect the quality of agricultural products, the standardization system of agricultural products quality should be updated to avoid the non-uniform standards of agricultural products. According to the latest quality standards issued by the state, ecommerce enterprises of agricultural products shall conduct quality tests for each product to be placed on the e-commerce platform. Strictly control quality, prevent the quality of unreasonable agricultural products in the market circulation

2) Through related technologies, the whole process of supervision from "field " to "dining table" can be realized. Relying on Internet technology, the whole process of positioning and tracking agricultural products is implemented. Avoid avoidable agricultural product losses due to improper distribution and warehouse facilities.

3) To achieve long-term development, cross-border e-commerce of agricultural products must strengthen the brand building of agricultural products. The market demand of cross-border ecommerce of agricultural products is closely related to the quality of agricultural products. However, in the e-commerce platform, it is difficult for consumers to accurately distinguish the quality of agricultural products through the graphic information of products on the e-commerce platform. Products without a brand or with a low reputation can hardly win consumers' trust, so their demand is usually small. Consumers will only choose the brands which has a good reputation. To improve the market share of cross-border e-commerce of agricultural products, the construction of 
agricultural products brand is particularly important.

\subsection{Cultivate Cross-Border E-Commerce Composite Talents}

In recent years, cross-border e-commerce of agricultural products has developed rapidly, but the staffing is not ideal. In the cross-border e-commerce environment of agricultural products, there is a severe shortage of interdisciplinary talents who not only need to understand the trade of agricultural products but also have e-commerce knowledge, which has a great impact on customer satisfaction. New talents should have Internet thinking, modern agricultural production methods and international trade knowledge. We should use its innovation consciousness to drive the development of cross-border e-commerce of agricultural products. To solve the problem of lack of interdisciplinary talents, a talent training system must be established.

1) The government, cross-border e-commerce enterprises and agricultural enterprises can conduct cross-training for personnel engaged in relevant work through academic exchange meetings. Through regular trainings, the members of the exchange meeting understand the basic knowledge of other industries and complete their own knowledge system. It can promote the smooth transaction process of cross-border e-commerce.

2) Strengthen cooperation between universities and enterprises, provide students with opportunities to practice in enterprises, and apply theories into practice, laying a foundation for future work related to cross-border e-commerce of agricultural products. It also enables schools to know what kind of talents are needed for cross-border e-commerce of agricultural products, so that the targeted training of students in school.

3) Set up a special cross-border e-commerce consultation service station for agricultural products to provide special guidance to enterprises involved in cross-border agricultural products trading and solve possible problems in cross-border agricultural products trading.

\section{References}

[1] Guogang Li, Jing Kong, 2013. Construction of logistics accessibility matrix based on the explained structure ISM model. Statistics \& Decision. 19(397), pp.42-44.

[2] Wei Liu, 2017. Research on the development path of cross-border e-commerce of Chinese agricultural products from the perspective of "smile curve" theory. Rural economy and science and technology. 28(19), pp.122-124.

[3] Xueqiang Luo, Lizhen Huang, 2017. Development strategy of agricultural products with Chinese characteristics under cross-border e-commerce environment. China Circulation Economy. Pp.67-71.

[4] Xianbing Ping, Yunmei Xiao, 2014. Research on the influencing factors of rural logistics based on the explained structure model -- a case study of Xiangtan in the context of urbanization. Logistics Sci-Tech. 1. Pp.5-8.

[5] Yongchao Yang. 2017. Research on development dynamics and innovative development of rural e-commerce in China under the background of supply-side reform. Journal of Commercial Economics. 5, pp.58-60.

[6] Yu Ding, 2016. Analysis of the characteristics and constraints of the development of cross-border e-commerce agricultural products trade in China. Practice in Foreign Economic Relations and Trade, 4, pp.37-39.

[7] Zhaoyang,Lu, 2018. Empirical study on factors influencing the development of cross-border agricultural products e-commerce [J]. Journal of International Trade, 4, pp.117-127. 